\title{
Roland Barthes: o Poder da Forma
}

\author{
Roberto José Ramos
}

Profesor da PUCRS-Brasil

Resumen: Autor de un bello texto, refinado por la marea digital de su singularidad, Rolando Barthes es una personalidad teórica y para dignatica. Él le ha dado status a la Semiología, extrayendo un objeto particular de su investigación. Él conoce como hacer de la Semiología una influencia media positiva, que ocurrió, especialmente, en el segundo período del siglo XX. Existe una perspectiva benéfica de revisar uno u otro aspecto de la propuesta diseñada por Barthes. La autenticidad de un criticismo para reencontrar ciertas lagunas, que encuentran la veracidad por una estructura profunda. El abre puertas al poder de la forma, inserto en el imaginario colectivo, como una pintura de la realidad.

Abstract: Author of a beautiful text, refined by the digital mark of his singularity, Rolando Barthes is a paradigmatic theoric personality. He gave a status to Semiology, extracting of it a particular research subject. He knows how to make Semiology to be a positive Media influence, that happen especialy second period of XX century.

There are salutary perspective of a review by one or another aspectt of the purpose, designed by Barthes. The autenticity of a criticism rencounter some lacunes, that found a veracity by a deep and structured theory. He open doors to Power of the Form, engraved in the collective imaginary, like a picture of reality.

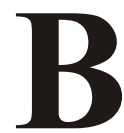

arthes legou uma produção bibliográfica, notabilizada pela qualidade de seu empreendimento teórico. Sublimou, com traços de sua singularidade intelectual, a essencialidade da linguagem. Fixou o olhar da Semiologia no desenvolvimento da Mídia, através das lentes invariantes do Estruturalismo.

Ele formulou conceitos, pertinentes à sua época, mas que a transcenderam. Avançaram no futuro. Tornaram-se presentes além das conjunturas temporais. As questões, implícitas, no Poder, no Mito e no "Fait Divers" tocam na invariância da instauração da subjetividade.

\subsection{Semiologia}

A Semiótica teve, em Barthes (1993:134), uma tonalidade específica. Ganhou uma nova denominação batismal. Foi ungida como Semiologia, estabelecida com conceitos:

A Semiologia é uma Ciência das formas, visto que estuda as significações, independentemente do seu conteúdo... Recordo, 
portanto, que toda a Semiologia postula uma relação entre dois termos, um Significante e um Significado.

A iluminação das formas, que o homem usa, para representar as suas realidades, é a geografia, onde se move a Semiologia. Ela caminha no território do quotidiano, desarrumando a arrumação dos álibis dos Signos, para revelar a clarividência do Poder.

A epistemologia barthesiana tem sido instabilizada por alguns prefixos "neo", "pós". Tais questionamentos, justificados por uma adolescência teórica, naufragam na tábua-rasa da superficialidade. Afogam-se nas gotas de uma estereotipia, que consagra um perfil pouco alinhado com a cientificidade.

Independente da prefixação, o endereço é o mesmo. Todos deságuam no mesmo mar. Buscam as águas da Matriz do Estruturalismo. É a invariância do paradigma do semiólogo francês, que possui, na forma, a invariante, como pressuposto norteador.

Na tecitura dos Signos, está o Poder, embrenhado na linguagem, no escaninho da língua, como um parasita atemporal. Não cessa de interpelar, colecionando súditos, materializando a imperatividade de sua vontade. Barthes (s.d.: 10-12) o enquadra conceitualmente:

... O Poder é a libido "dominandi", aí, está emboscado em todo e qualquer discurso, mesmo quando este parte de fora do poder... O Poder é parasita de um organismo transsocial, ligado à história inteira do homem e não somente a sua história política, histórica. Esse objeto, em se inscreve o Poder, desde toda a eternidade, é: a Linguagem e para ser preciso, sua expressão obrigatória: a Lingua.

O semiólogo concede tentáculos interdisciplinares à Semiologia. Inventaria a sua afinidade com a Psicanálise, criada por Freud, que desestabilizou a noção idealista de sujeito. Revelou que o homem não é determinado pelo seu consciente, porém pelo seu Inconsciente.

O conceito de Libido tem se prestado a diferentes interpretações. Alguns o emparedam na sinonímia do prazer sexual em uma postura redutora e simplificante. Outros conseguem caracterizá-lo com mais amplitude, traduzindo-o como energia prazerosa.

A primeira perspectiva não descobriu, ainda, a pluralidade da atuação da Libido. Não saiu da fase edipiana, onde a sexualidade é uma planice, que consegue tapar, com sua finitude, a silhueta infinita do horizonte. 
A outra perspectiva estabelece uma leitura mais pertinente com os textos freudianos. Ainda que a sexualidade seja o instinto mais forte no ser humano, há a evidência de outras formas prazerosas. A Libido é a energia prazerosa, própria do Instinto de Eros, que dá, ao homem, motivações para viver. Possui várias manifestações, uma das quais é a sexual.

O Poder, configurado por Barthes, é a energia prazerosa dominante. Significa a legitimação da vida, o seu pré-requisito indissociável. Independe de modelos e conjunturas sociais e especificidades temporais, mesmo que deles dependa a particularização de sua onipresença. Pronunciar-se pela Linguagem, através do seu código invariante: a Língua.

Nos aclives e declives do solo da Semiologia, Barthes teve engenho. Construiu um conceito de Poder, exemplar pelo seu sentido interdisciplinar, mas balizado pelo compromisso com a precisão. Adicionou, ao Estruturalismo, uma estrada vicinal com a dialética. Elucidou que a Invariância não é estática, mas toda a condição de movimento, agenciado pela supremacia do essencial em relação ao secundário.

Barthes (1979) salienta que a Semiologia e a Sociologia possuem objetos diferentes de estudo. A primeira se preocupa com a representação do real, através do imaginário; a segunda está fixada na concretude do real, pela pronúncia dos papéis e das práticas.

Tal distinção é pertinente, porém sustenta, na sua implicitude, o elo interdisciplinar entre a Semiologia e a Sociologia. Ambas convergem, em suas singularidades, para a dimensão social, inscrita nos escaninhos da linguagem e das práticas, que se encontram interrelacionadas.

Na Semiologia, a relação entre Significante e Significado é prioritária. O Significante é o plano de expressão; o Significado, o conteúdo. Ambos são indissociáveis. A associação deles estabelece o Signo. Os três constituem um Sistema de Significação.

Todo o signo está enraízado no seu contexto. Apenas constitui significado em determinado tempo e espaço, personificados socialmente. A sua produção, circulação e recepção estão conectadas com a especificidade de uma formação social, que o determina. 
No Mito, o esquema tridimensional - Significante, Significado e Signo -, está presente, como um Sistema de Significação segundo. O que é Signo, no primeiro Sistema, se converte em Significante do segundo, sublinha Barthes (1993).

O exemplo vem de uma foto da capa da Revista Paris-Match dos anos 50. Barthes (1993:138) detalha que a foto - um Significante -, denota "um africano, num uniforme francês, saudando a bandeira da França" - Significado. Há, também, a conotação de que "a França é um grande Império colonial”, possuindo, como Significante, todo o Signo denotativo.

O semiólogo (1993: 163) caracteriza o Mito, como uma forma de fala, despolitizada, produzida pela conotação. O "Mito não nega as coisas", apenas as torna inocentes, dando-lhes uma justificação natural e eterna, por intermédio do seu caráter interpelatório e imperativo.

O Mito não se define pelo objeto de sua mensagem, porém pela sua forma. Pode ser pronunciado por várias representações: uma foto, uma reportagem, um anúncio, etc... A sua função, na Mídia, é a naturalização e a eternização da sociedade burguesa. Usa mensagens factuais, denotativas, mas investindo na conotação.

O africano, na foto, é um figurante histórico. Foi guinchado da realidade, para simbolizá-la, historicamente, em carne e osso. Ganha o primeiro plano não pelos seus méritos existenciais, mas pela meritocracia de sua servidão auto-reconhecida.

$\mathrm{O}$ uniforme francês pesa mais do que qualquer peça do vestuário. Não emblematiza somente um abrigo corpóreo. Fixa o imaginário de uma subjetividade, que apenas existe e tem importância, quando endossa a sua desimportância de degrau, para a ascensão e ritualização do Império francês.

Tal qual o Mito, o semiólogo caracterizou a Ideologia, como uma forma de significação, realizada pela conotação. A sua função, também, se vê comprometida com a manutenção do projeto social burguês.

Observa-se que o Mito e a Ideologia são dois conceitos sobrepostos. Ambos são constituídos pela conotação e possuem funções idênticas, compatibilizadas com a reprodução social. Estão, ainda, permeados pelo conceito particular de Ideologia, em seu sentido pejorativo de "inversão, distorção", consagrada por Napoleão Bonaparte em 1812. 
Neste sentido, perante a tais evidências, não é uma demasia sustentar que o Mito e a Ideologia são sinônimos em Barthes. Apresentam, ainda que o autor não admita, conceitos e funções idênticos. Podem ser utilizados indistintamente. São um só, porque têm a mesma forma, como invariância.

Portanto, o Mito (ou Ideologia), em sua forma de fala conotada, não deve ser pensado, sem o Poder, a Libido dominante. Aquele, em suas funções de naturalização e eternização, é a própria instância de reprodução deste. Um só existe na medida da existência do outro.

\section{2 "Fait Divers"}

A expressão francesa "Fait Divers" designa, em sua generalidade, informação sensacionalista. Ela é bem anterior ao advento da Imprensa. Já existia em diferentes produções culturais, na Idade Média, habitando os cantos dos menestréis.

Vários pensadores se ocuparam, ainda que com brevidade, do "Fait Divers". Foi BARTHES (1971:263), que o dimensionou no plano da teorização. Ofereceu-lhe um conceito específico: "A informação monstruosa, análoga a todos os fatos excepcionais ou insignificantes, em resumo anônimos".

Os qualificativos eleitos por Barthes, falam com especificidade. A "monstruosidade", a "excepcionalidade", a "insignificância", sintetizados pela "anomalia", designam a informação sensacionalista tão entronizada pelos compêndios de Jornalismo no brete, conveniente, de um estilo.

Barthes (1971) transgrediu o perímetro conceitual. Arrumou-lhe uma tipologia básica, modificada por duas categorias: Causalidade e Coincidência. Ambas se subdividem em subtipos, direcionados, para a compreensão da excepcionalidade, introdutora da noção de conflito.

O primeiro tipo, o "Fait Divers" da Causalidade, apresenta duas manifestações:

a) Causa Perturbada: há o desconhecimento ou a imprecisão causal e quando uma pequena causa provoca um grande efeito;

b) Causa Esperada: quando a causa é normal, a ênfase recai em "dramatis personae" - criança, mãe e velho (Barthes, 1971:276-271).

Na Causa Perturbada, a excepcionalidade está localizada no porquê da factualidade. Existe um efeito, porém a causa é desconhecida ou 
deformada pela imprecisão ou pela ilogicidade. Em quaisquer das possibilidades, existe a formalização de uma situação de conflito.

$\mathrm{O}$ conflito vem à tona pela factualidade. Materializa-se, narcisicamente, no presente, porém conserva o motivo, recalcado, submerso no passado. O determinado é visto, solidificado pelo fato, embebido pela historicidade; o determinante, oculto, abstrato, deixando somente os indícios de seus domínio.

Verifica-se que há, formalmente, a estruturação de uma situação conflitiva. Esta interpela e obtém reconhecimento não apenas pelo dito, mas, primordialmente, pela forma de dizer. Ocorre a mimetização da dialética da subjetividade: a consciência é o dito, o efeito, o factual, o denotado, o determinado; a Inconsciência, o não dito, a causa, o contexto, conotado, determinante.

A condição de sujeito é uma condição conflitiva. O interpelado se reconhece nesta factualidade, trazida pelo "Fait Divers". Ele é, também, um efeito, em nível de consciência, com causas desconhecidas, imprecisas e ilógicas, mantidas no Inconsciente. Ao se reconhecer, vive o que está fora, como se fosse seu - Identificação Projetiva -, que enseja a Catarse.

$\mathrm{Na}$ Causa Esperada, a excepcionalidade troca de posição. Desloca-se para os protagonistas, que são responsáveis pela instauração do conflito. A dramaticidade apanha três tipos de sujeito básicos: criança, mãe e velho. Eles mimetizam os diversos ciclos do processo do existir humano.

A criança, a mãe e o velho simbolizam a fragilidade e a pureza humanas, decodificadas na dimensão do bem. Por suas próprias características, eles estão revestidos de circunstâncias trágicas. Não merecem a má sorte por caráter, porém acabam sendo vitimados, até por uma desatenção.

É possível verificar que tais sujeitos são estruturados pela Antítese da linguagem trágica. Simbolizam o bem, mas acabam por intermédio do Cúmulo, sofrendo. Estão assujeitados à condição de vítimas. Mobilizam emoções. Interpelam e são reconhecidos por suas importâncias no processo de sujeição, vinculado a qualquer interpelado. Oportunizam a Identificação Projetiva. É fácil se colocar no lugar deles pelas suas sacralizações, feitas pela moral e pela religião, e, em conseqüência, ocorre a Catarse, sob forma de piedade e de solidariedade. 
Mesmo que a Antítese trágica esteja presente na Causa Esperada, Barthes não a considera determinante. Ele prefere conceber a categoria, dando ênfase à excepcionalidade, fixada nos "dramatis personae" na especificidade, e à estrutura de Causalidade no aspecto geral.

Constata-se que, no "Fait divers" de Causalidade, através da Causa Perturbada e da Causa Esperada, existe a estruturação de um conflito, não-classificado pelo conhecimento humano. Torna-se inexplicável aos recursos da racionalidade e dos pressupostos da intelectualidade, ficando ininteligível na dimensão histórica.

Os sujeitos relativos não conseguem ter respostas para a situação conflitiva estabelecida. Ficam impotentes, sem recursos de compreensão. Recorrem a um Sujeito Absoluto, tal qual na Tragédia Grega, quando um "Deus-ex-Machina" entrava em cena, para contornar os impasses incontornáveis historicamente. Prevalece a lógica da fatalidade.

A Fatalidade do Real é o Sujeito Absoluto, o grande pai transcendental, que possui a explicação para o inexplicável. Representa a iluminação do oculto, o conhecimento do desconhecido pela onisciência e onipresença. Assume a responsabilidade sobre todas as coisas e a plenitude do todo. É o fiador perfeito para todas as imperfeições, inscritas na relatividade histórica da sujeição.

Tudo está pronto e harmonizado na Fatalidade do Real. É o espelho, por excelência. Interpela os sujeitos relativos, que se reconhecem, com liberdade, no seu poder e se tornam submissos diante do seu pleno e indizível saber, causa de todas as causas e suprema revelação de quaisquer enigmas de subjetividade.

No "Fait divers" de Causalidade, pelas singularidades da Causa Perturbada e da Causa Esperada, existe a estruturação de conflitos, que interpelam. São reconhecidos, porque reproduzem a dialética da subjetividade. Ensejam, por conseguinte, a Identificação Projetiva, que possui um final feliz, uma saída catártica: a Fatalidade do Real, o Sujeito Absoluto, garantia de harmonização e suprema desculpa para todas as culpas, desde que, com liberdade, seja pago o dízimo da submissão.

O segundo tipo, proposto por Barthes (1971: 271-274), é o "Fait divers" de Coincidência, subdividido em duas manifestações: 
a) Repetição: a informação repetida instaura a onipresença da factualidade em circunstâncias diferentes;

b) Antítese: duas perspectivas diferentes, distantes, antagônicas, são fundidas em uma única realidade. Uma de suas formas de expressão é o Cúmulo (a má sorte), figura da Tragédia Grega.

A Coincidência despe o homem de sua responsabilidade histórica. Conforta-lhe com a irresponsabilidade, desculpando as suas próprias culpas. Permite-lhe regredir a um estágio de menor idade, que lhe assegura a omissão diante de seus atos. É a garantia de transferir a responsabilidade para uma noção de destino, de fatalidade.

A Repetição da factualidade, sem uma logicidade histórica, remete para a noção de Coincidência. O repetir não é a reprodução do original, como cópia, porém a sua reprodução com diferenças, no desigual. Insinua a onipresença da factualidade, que se mantém em quaisquer circunstâncias.

O Inconsciente se reconhece, através da Identificação Projetiva, não pela reprodução do evento, originalmente, recalcado, mas por uma analogia formal do enfoque conflitivo. É onipresente, porque conserva o Mito pela repetição na desigualdade de diferentes circunstâncias.

A Antítese mistura os opostos, os antagônicos em uma mesma dimensão do real. Os dissociáveis se tornam indissociáveis, como se fossem gêmeos univitelinos. Os desiguais ficam igualados por uma inteligência não-materializada, sem significação corpórea, que reina na abstração. Uma de suas pronúncias é o Cúmulo, onde o trágico faz as vítimas.

Verifica-se que a Repetição e a Antítese estabelecem a Coincidência, reproduzindo a linguagem trágica, com o "Deus-ex-Machina", tal qual faz o "Fait divers" de Causalidade. Mesmo com outras particularidades, agora, também, o caminho é igual: a Fatalidade do Real, como Sujeito Absoluto, para desatar os nós coincidentes.

Os dominantes e os dominados, ricos e pobres, belos e feios compõem um rebanho harmônico, apesar de suas divergências. Possuem o mesmo ancoradouro. Compartilham, pelos atalhos da Causalidade e da Coincidência, do mesmo caminho: a Fatalidade do Real, uma categoria de fácil disponibilidade e de elástico uso no Senso Comum. 
Na teorização de Barthes (1971: 299) sobre o "Fait divers", o conceito de estrutura é essencial. Ele o explica do seguinte modo:

A estrutura é, pois, na verdade um simulacro do objeto, mas um simulacro dirigido, interessado, uma vez que o objeto imitado faz algo que permanecia invisível, o se preferirmos, ininteligível no objeto natural.

Barthes realiza um simulacro, dirigido do "Fait divers". Dá-lhe um conceito. Oferece-lhe estrutura com duas categorias: a Causalidade e a Coincidência. Ambas estão direcionadas para a classificação da excepcionalidade, fixada na dimensão do conflito, respectivamente, através da Causa Perturbada e Causa Esperada, da Repetição e da Antítese. Revela-lhe a Fatalidade do Real, como Sujeito Absoluto, análogo ao "Deus-ex-Machina" da linguagem trágica.

$\mathrm{Na}$ abordagem estruturalista, o mais importante não é o dito. As histórias, os protagonistas e as circunstâncias são variáveis no tempo e no espaço. São perecíveis. O que importa é a estrutura, a forma de dizer, o significante invariante, que tem permanência perante quaisquer possibilidades de mutação.

Vale destacar que não existe uma estrutura pura. Em qualquer "Fait divers", é possível encontrar características simultâneas de Causalidade e de Coincidência em interação. Nessa interrelação, todavia, há uma estrutura invariante, determinante da abordagem e identificado, por conseguinte, a sua tipologia e a sua conseqüente tipologia.

Em relação ao "Fait divers de Coincidência de Repetição, permite dois modos de aplicação. $\mathrm{O}$ primeiro se estrutura por qualquer factualidade, que se repita, o segundo se refere a qualquer tipo de "Fait divers", quando repetido. Esse, no caso, passa a ter duas estruturas, determinando duas tipologias simultâneas, uma delas, dependendo da situação, deverá prevalecer, constituindo uma classificação específica.

Barthes (1971) enfatiza que o "Fait divers" possui um consumo imediato. Notabiliza-se pela sua imanência. É fechado no seu próprio contexto, que é a única dimensão do seu saber. Não reivindica nada, que possa transcender o seu próprio território. Está preso no presente, cristalizado no aqui e no agora. É, por excelência, narcísico.

O "Fait divers", em suas diferentes manifestações, é utilizado na Mídia, com diversas abordagens. Aparece no tratamento da realidade e 
da ficção, seja nas telenovelas, nos telejornais, nos "talk-shows", nos programas de humor, no noticiário da Imprensa e na Publicidade.

O "Fait divers" é, por natureza, sensacionalista. Tanto pela Causalidade - Causa Perturbada e Causa Esperada -, e pela Coincidência - Repetição e Antítese -, interpela pela emoção. As suas estruturas são constituídas pelas anomalias e pelas excepcionalidades, marcadas, em essência, pela valorização do espetacular.

Em maior ou menor grau, a Mídia é sensacionalista por natureza. É o agente da interpelação, que busca o reconhecimento do interpelado e a sua conseqüente submissão. Está, também, submetido à audiência, aos patrocínios e ao lucro. À medida que a mensagem se encontra dominada pelo Valor de Troca, transforma-se em mercadoria. Não há como ela abdicar do Sensacionalismo, explícito ou implícito, mas presente.

$\mathrm{O}$ "Fait divers" se compatibiliza com a linguagem televisiva. Nessa, a imagem concisa, com a supremacia da exterioridade, onde reina a factualidade, expressa, pelo presente, a interpelação narcísica. A Televisão e o "Fait divers" estão voltados em mostrar e não demonstrar. Não solicitam nenhuma reflexão aprofundada, pois se notabilizam pela superficialidade, marcada pela emocionalidade.

O "Fait divers", em suas várias pronúncias, tem um Sistema de Significação, que denota a factualidade presente, embebida pelo conflito. Possui um interpelação narcísica com o receptor, que identifica, projetivamente, os seus conflitos inconscientes no formato conflitante da informação.

O Poder, no "Fait divers" é a expressão do domínio do individualismo, manietado pela emocionalidade. Não importa o uso da razão. O que conta e dá saldo é a exploração das emoções, reprimidas no Inconsciente, que emergem, através da Identificação Projetiva, responsável pela Catarse.

Tal Sistema de Significação, que denota o fato presente pelo olhar emocional, contrabandeia um outro sentido. Torna-se Significante da conotação, que, tal qual a estrutura trágica, com o "Deus-ex-Machina", estabelece a noção de Fatalidade do Real - o seu Sujeito Absoluto. Eis a sua síntese perfeita, modulada pela dialética hegeliana. 
A Fatalidade do Real é o Mito (Ideologia) do "Fait divers". Legitima o hegemônico, de perfil cultural e histórico, tornando-o natural e eterno pela sacralização de uma abordagem metafísica.

Portanto, a Semiologia, de Barthes, pronunciada, pela singularidade das categorias, "Fait divers", Poder e Mito (Ideologia), é pertinente para o estudo dos Meios de Comunicação Social. Enseja uma análise interdisciplinar do imaginário coletivo nos processos midiáticos de informação.

\section{Bibliografia}

Barthes, Roland. Mitologias. 9.ed., Rio de Janeiro: Bertrand Brasil, 1993. . A Aula. São Paulo: Cultrix, s.d.

. Ensaios Críticos. Lisboa: Edições 70, 1971.

Sistema da Moda. São Paulo: Editora Nacional e Editora da Universidade de São Paulo, 1979. 